\title{
O teatro da operação e a cena energética
}

\section{Resumo}

O artigo aborda questões relacionadas a uma certa modalidade de escritura cênica manifestada na contemporaneidade, cuja matéria espetacular (e sua imaterialidade) nunca é dirigida pelo espírito do encenador (ou de um coletivo), nem tampouco a ele se dirige. Isto dá ensejo à concretização de um tipo de "teatro da operação" que, ao mesmo tempo que elimina os direitos do autor, faz suprimir também as formulações de ordem conceitual e discursiva comuns ao "espírito ativo" - esprit actif - enquanto instância cuja destinação é questionar, de acordo com as demandas do sentido e da significação.

Palavras-chave: encenação; direção; operação; teatro energético

\section{Abstract}

This article approaches questions concerning to a specific branch of scenic writing manifested in contemporaneity, whose spectacular matter (and its immateriality) is never directed by the spirit of the director (or by the collective), nor is directed to it, giving opportunity to the concretization of a "theater of operation" that concomitantly eliminates the author's rights and also suppress formulations of conceptual and discursive order ordinaries to the "active mind" - esprit actif - as an instance whose destination is to question, according to claims of sense and meaning.

Keywords: staging; direction; operation; energetic theater

De acordo com Patrice Pavis, a encenação, enquanto escritura cênica fechada, resultante de um sistema semiológico de signos controlados por meio de um único olhar (do autor com seu estilo e método de atuação), atingiu o seu apogeu nos anos de 1960, e passou, a partir desse período, por uma fase de crise contínua. Na visão de Pavis (2010), os projetos de substituição do autor dramático por um autor cênico, nos termos do que preconizavam, por exemplo, Craig, Copeau e Strehler, acabaram por fracassar frente à realidade pós-moderna do mundo, cujos reflexos puderam ser percebidos diretamente na cena teatral. Isso porque, com a reviravolta ocorrida a partir dos anos de 1970, instalou-se um "cenário" pouco ou nada propício ao desenvolvimento do que seria o metatexto da encenação, inscrito ou ocultado numa determinada peça.

Além disso, em parte considerável das abordagens cênicas efetivadas a partir desse período, o trabalho do encenador passou a encerrar sempre um certo grau de indecidibilidade, tornando-se indeterminável, diferenciado. "O encenador, assim como antes dele 
o autor e depois dele o espectador, está submetido a uma 'destinerrância' - seu destino é errar de um lugar do texto para outro" (PAVIS, 2010, p. 57). A mixagem dos elementos cênicos começa, então, a não estabelecer qualquer tipo de discurso homogêneo, uma vez que a cena, deixando de ser orientada por um sujeito centralizador, passa a ser tomada por uma série de motivações espaciais que já não apontam para um ponto de convergência unificador.

Neste contexto, ainda de acordo com Pavis, sai de cena o mestre inconteste para dar lugar ao sujeito pós-moderno que, deliberadamente, perde e dispersa os seus poderes, ainda que continue a receber-Ihes os dividendos. Incorporando as contradições não sintetizantes, os "personagens" não figuráveis e as mudanças sucessivas de chaves de jogo, "o encenador não é mais o dono da atuação, ou pelo menos não o único dono: é apenas um sócio do autor e do ator, um "homem sem importância”" (Ibidem, p. 131). De modo que, para Pavis, a desconstrução contemporânea da encenação não implicou a sua superação como modelo de escritura cênica, nem tampouco eliminou a figura do encenador, o qual teria passado simplesmente a adquirir novas tarefas em decorrência do processo de emancipação da representação. Por essa perspectiva, tanto a noção de encenação, quanto a de encenador continuam a ser indispensáveis para a organização teatral contemporânea.

Diante de um tal posicionamento, caberia talvez questionar de início, com o próprio Pavis: "Podemos, temos que continuar a falar da encenação em geral como se os seus princípios não tivessem sido sistematizados no decorrer do século XIX?”(Ibidem, p. 376) ${ }^{1}$ - para acrescentar logo em seguida: "Será que não teríamos mesmo condições de renunciar à noção e ao método da encenação, mesmo nos casos em que a escritura cênica já não mobiliza qualquer tipo de pragmática de destinação comunicacional? Quando a matéria espacial já não se dirige mais ao espírito, nem se deixa apreender por qualquer forma de "espírito da representação" (Ibidem, p. 371)? Quando a materialidade cênica já não veicula qualquer modalidade discursiva oculta, nem mesmo na forma de uma "rica textura de mensagens"? Quando em vez de configurar um sistema implícito

\footnotetext{
${ }^{1}$ Sobre esse aspecto, talvez caiba atentar para a seguinte questão: se para fins de análise do teatro atual, a noção de "encenação", segundo o teórico francês, adquire uma plasticidade enorme, tornando-se nesse sentido "elástica" (Ibidem, p. 376), por que não estendê-la também às manifestações teatrais desenvolvidas em períodos prévios às experiências de Zola e Antoine?

${ }^{2}$ Carlson usa a expressão "rica textura de mensagens" (CARLSON, 1995, p.450) ao se referir a um comentário feito por Peter Brook à peça Marat/Sade, de Weiss. A ideia subjacente à mesma, contudo, transcendendo a esfera da dramaturgia e refletindo-se de forma decisiva no campo da encenação teatral, está atrelada a uma perspectiva
} 
de organização de sentido "controlado por um encenador ou por um coletivo" (Ibidem, p. 3), o espaço figural passa a materializar uma espécie de "instalação visível à distância" (Ibidem, p. 212)? Para todos esses casos, seria mesmo a noção de encenação "insubstituível" (Ibidem, p. 376)?

\section{Cena maquínica}

No seu projeto do Livro, Mallarmé introduz a figura de um mestre de cerimônias - espécie de antiator - que, não sendo um mero recitador de poesia, nem tampouco atuando nos moldes representacionais de um ator comum, é por ele designado "operador." Como nos lembra Puchner (2002), tal terminologia, sugerindo algo como a operação de uma máquina, satisfazia Mallarmé à medida que permitia uma abordagem do processo de criação por um viés rigorosamente impessoal, rompendo de vez com a ideia de uma criação subjetiva. E esse aspecto mecanicista acabava sendo ainda mais reforçado pelos cálculos matemáticos obsessivos que perpassam todo o projeto (pois além das notas detalhando, de forma precisa, aspectos da composição final do Livro e da coreografia de sua leitura, há, ainda, um grande número de gráficos esquemáticos que dizem respeito ao gênero do Livro nos termos de sua forma textual e teatral; número de convidados, bancadas, assentos, folhas, sessões etc). Para Mallarmé, interessavam acima de tudo nesse tipo de automatização do processo de criação, as diferentes permutações passíveis de operação por meio dos vários arranjos de folhas soltas (devidamente numeradas); assim como as possibilidades de sentido derivadas dessa ars combinatoria.

Por outro lado, esse automatismo, de acordo com indicações contidas no próprio Livro, deveria reter, sempre, um certo grau de "mistério"- termo que, aliás, costumava ser empregado por Mallarmé em suas referências aos efeitos mobilizados por sua estética simbolista de forma geral. De acordo com Puchner, no caso do Livro isso se reflete pelo caráter cerimonial de sua leitura performática, esse "meio-termo" que parece desempenhar a mediação entre o teatro e o livro. Sobre esse último aspecto, porém, Blanchot (1984) sustenta que, embora seja possível aproximar a leitura do Livro de um tipo de cerimonial sagrado - com traços de prestidigitação, teatro e liturgia católica -, não se pode desconsiderar o fato de que o operador, não sendo um leitor vulgar, também não era um autor ou um intérprete privilegiado capaz de tecer comen-

que tende valorizar a emissão de mensagens múltiplas, "que se acotovelam, se atropelam, se amontoam" conforme comentário do próprio Brook - atiçando a inteligência, a memória e as emoções; em detrimento de uma emissão mais restritiva e simplista do ponto de vista semântico. 
tários sobre o texto, no sentido de fazê-lo passar de um sentido a outro ou de mantê-lo em movimento entre todos os sentidos possíveis. O operador, nesse caso, não seria propriamente um leitor. Ele seria, de fato, a leitura. Por esse viés, a operação, enquanto leitura, é "a obra que se realiza suprimindo-se, que se prova confrontando-se consigo própria e se suspende ao mesmo tempo que afirma" (BLANCHOT, 1984, p. 254).

De modo que, para Blanchot a palavra "operação", ao conservar não só o sentido que Ihe advém da palavra "obra", como também adquirindo a acepção quase cirúrgica que lhe confere o seu caráter técnico, passa a ter valor correspondente ao de "supressão". Subtrai-se o tempo da narrativa, à medida que se opta por mostrar, em vez de contar 3 . Elimina-se o conceito, uma vez que se opera apenas na esfera onde a arte é pura linguagem. Por fim, suprime-se o direito de autor, de modo a impedir que até mesmo o operador (leitor) saiba de antemão "o que é o livro, nem se ele é, nem se o devir a que o livro responde ao mesmo tempo que o constitui com a sua supressão infinita tem desde já um sentido para nós ou terá alguma vez um sentido" (Ibidem, p. 254).

Considerando-se alguns dos aspectos que perpassam a ideia da operação (e do operador) no projeto do Livro de Mallarmé - dentre os quais, a supressão do autor e/ou do intérprete privilegiado, assim como a substituição da expressão de ideias ou emoções pelo automatismo -, pode-se perceber porque tanto Badiou, nas conjecturas que faz a respeito de uma possível cena do porvir ${ }^{4}$, quanto Deleuze, ao se referir à mecânica da subtração mobilizada pelo teatro de Carmelo Bene, fazem uso da mesma ${ }^{5}$. Operação e operador, nesse sentido, parecem ser termos adequados para se nomear um teatro (e cada um daqueles que o agenciam) livre das amarras da representação, da encenação, da interpretação, do sentido e da autoria.

\section{Imagem Pobre}

Em meio a uma conversa com Elie During, publicada por ocasião da exposição Um teatro sem Teatro, Alain Badiou comenta que a invasão da cena teatral contemporânea

\footnotetext{
${ }^{3}$ O que não implica a eliminação de todo tipo de temporalidade, nem a não permanência de algum tipo de narrativa. Como o próprio Blanchot sustenta, "'...evita-se a narrativa'. Por que se evita a narrativa? Não só porque se elimina o tempo da narrativa, mas porque em vez de contar, se mostra (Ibidem, p.252). Sobre esse mesmo aspecto, Lyotard, ao discorrer sobre o "sopro" que aspira o espírito para o abismo quando se instaura a paisagem, afirma que "a paisagem ergueu-se 'primeiro' diante do espírito (...) essa destreza quebrou-o, 'desapossou-o' (como se desapossa um soberano), fê-lo vomitar em direção ao nada do ser-ali” (Lyotard, 1997, p.188).

${ }^{4}$ A ser orientada por aspectos puramente abstratos e não mais pelos "axiomas de representação" designados pelo homem das instruções, ou seja, o encenador (Cf. BADIOU, 2007, p.23).

5 “O homem de teatro não é mais autor, ator ou encenador. É um operador"(DELEUZE, 2010, p.29) ou (Idem, 1997, p.241).
} 
pelos esquemas e procedimentos próprios à dança, à performance e outras práticas corporais acabou por indicar, de forma clara e indubitável, o fim do século do encenador; figura que, durante pouco mais de um século, adquiriu uma crescente importância no campo teatral, ao assumir o papel de homem das instruções ou dos axiomas da representação. Para Badiou (2007), no entanto, o fim da hegemonia do encenador não deve ser tomado como um indício do que poderia vir a ser o fim do próprio teatro. Como forma de refutar essa ideia, sustenta que o teatro existiu por um longo período sem a figura apartada do encenador, podendo, portanto, continuar a existir sem a mesma. Para o filósofo, a grande questão que se impõe no atual cenário é saber o que passa então a centralizar as instruções, por mais aleatórias que elas possam ser. Sobre esse ponto, Badiou revela em seguida que, a julgar pelo seu sentimento, tais instruções deverão se tornar cada vez mais abstratas, e não corporais ou coletivas.

Em certa medida, as considerações de Badiou nos remetem a algumas observações feitas por Deleuze sobre o que este designa como a Língua III de Beckett (e que incluiu de forma enfática os trabalhos televisivos do artista). Ao substituir as projeções por tabelas e formulações destituídas de sentido, essa variante da linguagem beckettiana, de acordo com Deleuze, promove - com a mais elevada exatidão - a mais extrema dissolução do sujeito. Diferentemente do que ocorre na Língua I (maculada pela razão), e na Língua II (maculada pela memória), na Língua III atinge-se o ponto no qual já não se remete mais a linguagem à qualquer voz emissora. Tampouco há a retenção de qualquer coisa pessoal. É a língua não mais dos nomes, das vozes e das palavras, mas, antes, das imagens puras - sonantes e colorantes.

Segundo Deleuze, é muito difícil fazer uma imagem desse tipo. Isto é, uma imagem que, em toda a sua imparidade, não seja mais que uma imagem, ainda que o seu conteúdo seja bastante medíocre, bastante pobre, pois a força da imagem não se define pelo aspecto sublime do seu conteúdo, mas antes por sua "tensão interna". Ou ainda, pela força que ela aciona, seja por se sustentar no vazio - imagem imóvel -, seja por estremecer no aberto - imagem trêmula -, como um pequeno ritornelo visual e sonoro. De acordo com o filósofo, é extremamente raro alcançar o ponto em que a imagem, destituída de toda marca de pessoalidade e racionalidade, surge sem máculas de ordem representacional, amnésica, alógica, quase afásica, de modo a afrouxar o torniquete das palavras, secar a ressudação das vozes. 
Não sendo um objeto, a imagem é, acima de tudo, um processo que faz aceder ao indefinido e ao estado celestial. Nesse sentido, o que mais importa não é o conteúdo pobre, mas a liberação explosiva de uma espécie de "energia captada", o que, por sua vez, faz com as imagens, ao se confundirem com a detonação, a combustão, dissipação de energia, passem a ter uma curta duração; captando todo o possível, a imagem dura o tempo exato de permanência do nosso prazer, de nosso olhar, para logo em seguida fazer saltar o fim. A imagem é o que extingue, uma queda.

Ao abordar aspectos tais como a supressão das marcas de personalidade, racionalidade, intencionalidade - "máculas" de ordem representacional - algumas dessas considerações de Deleuze sobre a Língua III trazem à tona questões que parecem estar diretamente associadas ao que Badiou reconhece na forma de um indubitável desfecho daquele que teria sido o "século do encenador".

\section{Cena energética}

A questão da "ausência de intencionalidade" associada à Língua III encontra franca reverberação também no texto O Dente, a Palma, de Lyotard. Nele, o autor faz uma espécie de projeção de uma cena que, superando o niilismo típico das modalidades representativas e suas estruturas hierárquicas de poder - em meio às quais um dado significante (b) está sempre sendo submetido a um outro dado significado (a) rompe de vez com toda teleologia, toda sintaxe e todo padrão semiótico, de modo a libertar fluxos de libido e deslocamentos de afetos.

De acordo com a concepção do filósofo francês, o teatro energético instaura um espaço-tempo pleno de descontinuidades, com autonomia e simultaneidade de sons-barulho, palavras, arranjos corporais, imagens que o filósofo reconhece, por exemplo, em co-produções de Cage, Cunningham e Rauschenberg. Neste ambiente em que se abole a composição sígnica, a relação de poder se torna impossível. Assim sendo, não há mais espaço para o predomínio de quem quer que seja - dramaturgo, encenador, coreógrafo, cenógrafo - nem tampouco submissão do signo e do espectador, uma vez que o teatro energético, rompendo com temáticas e assuntos, passa a jogar com vistas à produção de alta intensidade (por excesso ou falta de energia) do que está presente, sem intencionalidade. Nada de A no lugar de B (ou vice-versa), nem A no lugar de $X$ (não há uma incógnita a ser decifrada). Nada de letra ou símbolo. Nada de 
caráter. O teatro energético escapa a esses arranjos binários e tampouco se dá a ler, antes apenas a sentir - o que em mim sente está pensando ${ }^{6}$.

Ao discorrer - já num outro ensaio - sobre o que caracteriza um tipo de pensamento verdadeiramente imbricado aos afetos humanos, Lyotard declara que tal pensamento não se estabelece através da seleção de dados e da sua articulação, uma vez que "os dados não são dados mas dáveis e a seleção não é uma escolha. Pensar, assim como escrever ou pintar, é quase só receber o que nos chega a partir dos dados" (LYOTARD, 1997, p. 26). Assim sendo, de acordo com o filósofo, tal forma de pensamento requer um tipo de suspensão dos motivos habituais do espírito associados ao habitus, às disposições do corpo, aproximando-se do esvaziamento mobilizado pelo artista-guerreiro japonês ao caligrafar, ou do comediante ao atuar - o que implica a suspensão do espírito ativo e, consequentemente, a interrupção de qualquer processo de direcionamento da matéria.

O que nada tem a ver com a "tabula rasa", com o que se pretendia (em vão)
em Descartes, que o pensamento conhecedor começasse do zero, o que,
paradoxalmente, só pode ser um recomeçar do zero. Mas naquilo a que
chamamos pensar, o espírito não é por nós "dirigido" mas suspenso. Não lhe
fornecemos regras mas ensinamo-lo a acolher. Não desbastamos o terreno
para construir com mais luz, entreabrimos uma clareira onde a penumbra do
quase dado poderá entrar e modificar o seu contorno. (...) Este pensamento
não tem qualquer ligação especial com a combinação estabelecida de
símbolos. (...) A dor de pensar não é um sintoma que, vindo de qualquer
parte, se instala no espírito em vez de ocupar o seu verdadeiro lugar. É o
próprio pensamento em si que, convertido à irresolução, decide tornar-se
paciente e querer não querer, querer, exatamente, não querer dizer em vez
do que deve ser significado (LYOTARD, 1997, p. 27).

Para Lyotard, este tipo de lançamento no vazio, de evacuação, demandando uma ruptura radical com qualquer atividade identificatória, seletiva ou conquistadora, não pode acontecer sem sofrimento. De acordo com o filósofo, a graça de que falava Kleist - associada à concepção aristotélica do automatismo divino, assim como à ausência de qualidade e, por conseguinte, de potência - não se deixa ser conquistada, "ela chama-se" (LYOTARD, 1997, p. 27). Neste sentido, faz-se necessário promover uma espécie de suspensão que desobstrua o corpo e o espírito como meio de fazer com que eles sejam tocados pela énergéia; o que, para Lyotard, só se estabelece por meio de uma inexorável carga "analogisante" (SIBILIA, 2002, p. 100), que inclui o "sofrimento e o sexo" (Ibidem, p.100), posto que um acontecimento dessa natureza, para

\footnotetext{
6 “...não devemos tentar pensar a 'percepção' (que palavra!) dessa matiz, como uma inscrição sobre um suporte (...) é necessário tentar pensar uma marca que, em vez de marcar, de "tipar" (Lacoue-Labarthe) uma superfície passível, a anularia (Lyotard, 1997, pp. 159).
} 
além de estar diretamente ligado às circunstâncias materiais da existência humana, implica também uma necessária perda do prazer do adquirido. Não por acaso, ao se referir ao seu teatro energético, o qual escapa aos modelos de significação "conquistáveis", “adquiríveis", “agarráveis", Lyotard, recorrendo a um exemplo de Hans Bellmer, faz remissão direta a um determinado tipo de sensação ligada à dor: Tenho terríveis dores de dente. Cerro o punho, as unhas se cravam na palma da mão. Duas concentrações de energia. Isso quer dizer que o gesto da mão representa, ilustra a dor de dente? O signo é de quê? ${ }^{7}$

\section{Referências}

BADIOU, A.; DURING, E.. Um Teatro da Operação: uma conversa entre Alain Badiou e Elie During. In: Um teatro sem teatro. Catálogo da exposição organizada pelo Museu d'Art Contemporani de Barcelona e co-produzida com o Museu Colecção Berardo - Arte Moderna e Contemporânea de Lisboa, 2007.

BELLONI, Arthur E. A. Teatro Menos Teatro. São Paulo: ECA/USP, 2011. (Tese de Doutoramento). BLANCHOT, Maurice. O livro por vir. Lisboa: Relógio d’Água Editores Ltda, 1984.

CARLSON, Marvin. Teorias do teatro. São Paulo: UNESP, 1995.

COWELL, C. Deleuze and Foucault: Series, Event, Genealogy. Theory \& Event - Volume 1, Issue 2. The Johns Hopkins University Press, 1997.

DELEUZE, Gilles. One less manifesto. In: MURRAY, Thimothy. Mimesis, masochism \& mime. The politics of theatricality in contemporary French thought. The University of Michigan Press, 1997, pp. 239-258.

Sobre o teatro. Rio de Janeiro, Jorge Zahar Editor Ltda, 2010.

KRAUSS, R. Caminhos da Escultura Moderna. São Paulo: Martins Fontes, 2007.

LEHMANN, Hans-Thies. Teatro Pós-dramático. São Paulo: Cosac Naify, 2007.

LYOTARD, Jean-François. The tooth, the palm. In: MURRAY, Thimothy. Mimeses, masochism \& mime, the politics of theatricality in contemporary French thought. Ann Arbor: The University of Michigan Press, 1997. pp. 282-288.

O Inumano. Lisboa: Editorial Estampa, 1997.

PAVIS, Patrice. A encenação contemporânea. São Paulo, Perspectiva, 2010.

PUCHNER, M. Stage fright: Modernism, anti-theatricality \& drama. Baltimore e Londres: The Johns Hopkins University Press, 2002.

SIBILIA, Paula. O homem pós-orgânico: corpo, subjetividade e tecnologias digitais. Rio de Janeiro: Relumé Dumará, 2002.

\footnotetext{
${ }^{7}$ Cf. LYOTARD apud LEHMANN (2007, p.58) ou LYOTARD (1997, p. 283). ). De acordo com Lehmann, ao mobilizar forças, intensidades e afetos, o teatro energético sugerido por Lyotard parece estar mais próximo do conceito de mimese de Adorno - "que a compreende como uma equivalência pré-conceitual, afetiva, no sentido do mimetismo de Roger Caillois" (LEHMANN, 2007, pp.58-59) - do que com a mimese propriamente dita, vinculada aos modelos representacionais.
} 